\section{Delayed Cure}

Case 216 is classed as a failure though his blood pressure was reduced from $195 / 125$ to $160 / 105$ for one year, and he actually had some pre-operative readings of $190 / 140$. The reason for this is the relatively short follow-up period. If he remains well at the present level for three years he might be reviewed later as a possible cure. This also applies to Cases 29 and 30. Case 14 is claimed under the $20 \%$ reduction as a success in view of vast clinical benefit maintained for four years; actually the diastolic pressure has continued to fall and is now $85 \mathrm{~mm}$. $\mathrm{Hg}$, and he could be regarded as a cure by any standards; a further justification of the $20 \%$ allowance. Case 218 is a late failure after eight years' relief. Case 16 is the only one that would not justify the $20 \%$ reduction, for though the diastolic pressure fell from 140 to $110 \mathrm{~mm}$. $\mathrm{Hg}$ for three years, it then relapsed to $130 \mathrm{~mm}$. $\mathrm{Hg}$. $\mathrm{He}$ is therefore classified as a failure.

The $20 \%$ reduction in diastolic pressure seems to be justified as an additional claim for cure if there is marked clinical benefit and the follow-up is extended for three years. Also it would be better if "good result" or "good effect" were claimed rather than "cure."

\section{Summary and Conclusion}

The literature on the subject of nephrectomy for hypertension is discussed and reasons for a more optimistic approach to this problem are advanced Agreement is noted on the investigations required.

E:ghty-nine personal cases of nephrectomy for unilateral renal disease in hypertension are reviewed and 66 accepted for analysis.

Criteria for a claim of success are discussed and a new standard is suggested.

The 66 nephrectomies have been analysed and a $45.5 \%$ cure is claimed, for which a diastolic pressure of $90 \mathrm{~mm}$. $\mathrm{Hg}$ for one year is required. In addition, a few patients symptomatically cured for three years with a $20 \%$ fall in the diastolic pressure (even if remaining above $90 \mathrm{~mm}$. $\mathrm{Hg}$ ) are included.

If the additional claim of those with a $20 \%$ fall in diastolic pressure is rejected, the claim for cure is $37.9 \%$.

The younger the patient the better the result.

Patients over 50 seldom benefit unless the hypertension is recent.

While every patient must be considered and assessed as an individual problem it is hoped that a more optimistic approach may be made to these cases. Certainly hypertension in young people must be investigated for a renal cause, and early nephrectomy of a suspected kidney will offer these patients a $50 \%$ chance of cure. The number of patients who have been adversely affected by such treatment must be very small; I have not encountered any.

It is recommended that a diastolic pressure of $90 \mathrm{~mm}$. $\mathrm{Hg}$ be required for one year to claim a good result, but that patients who have been symptomatically cured for three years with a $20 \%$ fall in the diastolic pressure should also be included as good results.

I thank Mr. P. Holmes, Mr. C. Q. Henriques, Miss Gadsby, and Miss Henriksen for help in tracing the follow-up of cases.

\section{REFERENCES}

Adams, J. C. L., and Newman, M. J. D. (1958). Brit. med. J. 1, 562

Ask-Upmark, E. (1929). Acta path. microbiol. scand., 6, 383.

Braasch, W. F. (1942). Canad. med. Ass. J., 46, 9.

Butler, A. M. (1937). J. clin. Invest. 16, 889 .

Gellman, D. D. (1958). Quart. J. Med., 27, 103.

Goldblatt, H., Lynch, J., Hanzal, R. F., and Summerville, W. V. (1934). J. exp. Med., 59, 347.

Heritage, K. (1943). Proc. roy. Soc. Med., 36, 551

Kreutzmann, H. A. R. (1947). J. Urol. (Baltimore), 57, 467.

Levitt, W. M., and Oram, S. (1956). Brit. med. J., 2, 910.

Maitland, A I. L. (1952). Proc. roy. Soc. Med., 45, 731.

Poutasse, E. F., and Dustan, H. P. (1957). J. Amer. med. Ass.,

Ratliff, R. K., Nesbit, R. M., Plumb, R. T., and Bohne, W. (1947). Ibid., 133, 296.

Schaffer, A. J., and Markowitz, M. (1954). Amer. J. med. Sci., 227, 417.

Smith, H. W. (1956). J. Urol. (Baltimore), 76, 685.

Thompson, G. J. (1957). Ibid., 77, 358.

Thompson, J. E., and Smithwick, R. H. (1952). Angiology, 3, 493.

Wilson, C. (1957). Brit. J. Urol., 29, 348.

- and Byrom, F. B. (1939). Lancet, 1, 136

Winter, C. C. (1957) J Urol (Baltimore) 78, 107.

Yates-Bell, J. G. (1952). Proc. roy. Soc. Med., 45, 737.

\section{TUBERCULOSIS OCCURRING DURING STEROID THERAPY}

BY

JOHN MACKINNON, M.D., M.R.C.P.

Lecturer in Cardiology in the University of Manchester: Honorary Consultant Physician, Manchester Royal Infirmary; Formerly Senior Medical Registrar. Crumpsall Hospital

There is much evidence that steroids facilitate the spread of tuberculosis in susceptible animals (Hart and Rees, 1950 ; Spain and Molomut, 1950; Karlson and Gainer, 1951). Dissemination from a tuberculous lesion during steroid therapy in man has been reported (Popp et al., 1951), and also its appearance during or soon after treatment in individuals previously presumed to be unaffected (King et al., 1951; Kleinschmidt and Johnston, 1951 ; Fred et al., 1951 ; Harris-Jones and Pein, 1952 ; Davidson et al., 1953 ; Hill and Kirshbaum, 1956).

In view of the increasing use of more powerful steroids it is thought justifiable to report the cases of three more patients who developed tuberculosis during treatment. In two the disease was widely disseminated, and none were suspected of having tuberculosis before treatment started.

\section{Case 1}

A housewife aged 58 was referred to Dr. E. G. Wade in April, 1956. In 1937 she had had a cervico-dorsal sympathectomy performed for Raynaud's disease, which had begun two years previously. Soon afterwards she developed dysphagia which became increasingly severe, and investigation by $\mathrm{Mr}$. Gordon Jack in 1953 revealed a benign oesophageal stricture associated with ulceration and a small hiatus hernia. The dysphagia was not relieved by dilatation, and on January 22, 1954, the hiatus hernia was repaired, the stricture was dilated, and some enlarged paroesophageal glands were excised. Histological examination of these glands was not helpful and there was nothing to suggest tuberculosis.

For a time normal swallowing was restored, then dysphagia recurred, requiring frequent dilatation without much improvement. In January, 1956, she developed painless oedema of both feet and was referred to hospital 
in April. When first seen she showed the typical rash of chronic discoid lupus erythematosus on the face, upper chest, and hands which she said had been present for 12 to 18 months. The skin over the fingers was "tight" and atrophic, limiting movements at the interphalangeal joints. Small lymph nodes were palpable in both axillae, groins, and supraclavicular fossae. There was moderate cardiac enlargement, but the heart sounds were normal and there was no evidence of any valvular lesion. The blood pressure was $190 / 110 \mathrm{~mm}$. Hg. The lungs were clear and the liver and spleen were not palpable. The central venous pressure was not raised, but there was moderate pitting oedema of both feet and sacrum. The optic disks and retinae showed no abnormality. The urine contained a heavy cloud of albumin.

A provisional diagnosis of chronic discoid lupus erythematosus with systemic involvement was made, and the patient was admitted to the ward. The diagnosis was confirmed by the demonstration of L.E. cells in the peripheral blood and investigations resulted as follows: Hb, $64 \%$; R.B.C., $4,020,000 /$ c.mm. ; W.B.C., 3,600/c.mm. ; E.S.R., $50 \mathrm{~mm}$.; serum albumin, $1.6 \mathrm{~g} . / 100 \mathrm{ml}$; ; serum globulin, $3.1 \mathrm{~g} . / 100 \mathrm{ml}$. ; serum bilirubin, $0.1 \mathrm{mg}$. $/ 100 \mathrm{ml}$. thymol turbidity, 1.6 units; serum alkaline phosphatase, $13 \mathrm{~K}$-A units ; blood urea, $36 \mathrm{mg}$. $100 \mathrm{ml}$. ; urea clearance, $61 \%$. Blood W.R. and differential agglutination tests were negative.

Chest $x$-ray examination showed left ventricular enlargement but no pulmonary abnormality. The E.C.G. showed negative $T$ waves in the left precordial leads.

Prednisone (40 mg. daily) was started on May 28 and was steadily reduced to $5 \mathrm{mg}$. daily by June 19 . Chloroquine (200 mg. daily) was also given during this period. The patient showed subjective and objective improvement. The rash almost disappeared, the oedema subsided, and her exercise tolerance improved. The albuminuria and dysphagia, however, were unchanged. She was discharged from hospital on June 23 , taking prednisone $5 \mathrm{mg}$. daily. A month later the haemoglobin had risen to $84 \%$, though the E.S.R. remained high $(47 \mathrm{~mm}$.). When she attended the out-patient department on August 7, she was not well. Ten days previously she had had a "home-perm," and 48 hours later numerous painful blisters had appeared on the forehead, face, and upper chest.

On examination she was afebrile. Her lips and face were red and oedematous, and large weeping areas appeared on the forehead, extending to the hair-line and involving the face, neck, and upper chest. There were many small ulcers on the buccal mucosa. The original rash on the fingers, hands, and face was almost indiscernible. The blood pressure was $110 / 70 \mathrm{~mm} . \mathrm{Hg}$, and there was a trace of oedema. The lymph nodes noted previously were unchanged. There were no abnormal physical signs in the lungs or abdomen. The differential diagnosis lay between an acute sensitization dermatitis to the "home perm" with secondary infection, a relapse of the disseminated lupus erythematosus, and acute staphylococcal bullous impetigo. Investigations at this time resulted as follows: $\mathrm{Hb}, 76 \%$; W.B.C., 2,300/c.mm.; E.S.R., $50 \mathrm{~mm}$. ; serum albumin, 2 g. $/ 100 \mathrm{ml}$.; serum globulin, $3.6 \mathrm{~g} . / 100 \mathrm{ml}$. The urine contained a heavy cloud of albumin (Esbach $5 \mathrm{~g}$./litre). L.E. cells were present in the peripheral blood.

Local application of $1 \%$ chlortetracycline cream to the face brought improvement, but on August 11 the appearance of numerous large bullae on the feet was considered to be due to a relapse of the disseminated lupus erythematosus. The dose of prednisone was increased and was followed by immediate improvement. By August 26 the rash on the face and chest had practically cleared. Three days later, however, her condition again deteriorated and she began having periods of confusion and disorientation. There were no abnormal neurological signs and the optic disks and fundi were normal. $X$-ray examination of the chest on August 31 showed no abnormality in the lung fields. On September 3 she developed a low-grade pyrexia associated with a rising pulse rate and increasing oedema. The blood pressure was $130 / 80 \mathrm{~mm}$. $\mathrm{Hg}$, and blood urea $30 \mathrm{mg}$./ $100 \mathrm{ml}$. The fever persisted in spite of penicillin; she became increasingly disorientated, lapsed into a coma, and died on September 28, 1956.

\section{Post-mortem Findings}

The body was that of an elderly woman with pitting oedema of the legs and lower abdomen. Skull, dura, venous sinuses, and brain were normal. The lower third of the oesophagus was slightly dilated and contained a large chronic ulcer, $1 \mathrm{~cm}$. in diameter. The pericardium was adherent to the heart owing to old fibrous adhesions. The heart showed left ventricular hypertrophy, but the valves, endocardium, and myocardium appeared healthy. Both pleural cavities were dry and there were a few old fibrous adhesions over the left lower lobe. The lungs were slightly oedematous. The tracheo-bronchial lymph nodes were slightly enlarged and contained white opaque material. The peritoneal cavity, liver, spleen, and abdominal lymph nodes appeared healthy. The kidneys were normal on macroscopic examination.

Histology.-Foci of caseous necrosis were found in many organs-spleen, lungs, kidneys, liver, and lymph nodes. These were surrounded by epithelioid cells with a few Langhans type giant cells, particularly those in the spleen. There was more caseation than would normally be expected from the size of the lesion and little or no fibrosis. The lymphocytic response was less marked than normal. The tracheo-bronchial lymph nodes contained a more extensive and presumably older lesion. Sections stained for tubercle bacilli showed abundant organisms in the lymph nodes but somewhat fewer in the miliary lesions. Kidneys: The capillary basement membrane of the glomeruli showed some thickening with occasional foci of fibrinoid degeneration compatible with active disseminated lupus. Spleen: Many of the arteries were surrounded by concentrically arranged fibrous tissue, giving the typical appearance seen in disseminated lupus. Other organs showed no significant abnormality; in particular no other vascular lesions were found.

\section{Case 2}

A housewife aged 49 was referred to Dr. E. G. Wade in April, 1956, by Dr. Rupert Sykes, who had first seen her on December 13, 1954, when she complained of increasing breathlessness and productive cough of three years' duration. She had worked in the card-room of a cotton mill for 16 years and gave a history of pneumonia in 1953. A mass miniature radiograph of the chest in 1951 had been reported as normal, but an $x$-ray film in December, 1954, showed diffuse infiltration in both lung fields extending out from the hilar regions. At this time she was cyanosed and her fingers were clubbed. Persistent crepitations were audible at both lung bases and the blood pressure was $120 / 85 \mathrm{~mm}$. Hg. No cardiac abnormality was detected, there were no enlarged lymph nodes and no rash, and the liver and spleen were not palpable. Investigations gave the following results: Hb, $120 \%$; R.B.C., 7,050,000/c.mm. ; W.B.C., $11,000 /$ c.mm. ; serum albumin, $4.1 \mathrm{~g} / 100 \mathrm{ml}$.; serum globulin, 3.9 g./ $100 \mathrm{ml}$. ; no L.E. cells in peripheral blood; E.C.G. was normal ; repeated examinations of sputum for tubercle bacilli were negative.

Various antibiotics were without effect either on the pulmonary crepitations or on the radiological appearances. Cortisone produced subjective improvement only, and while on this treatment on October 14, 1955, she developed a right homonomous hemianopsia which was thought to be of vascular origin, and the cortisone was stopped.

She was admitted to hospital on April 5, 1956. At this time she was severely incapacitated and could walk only about 20 yards slowly. She had a productive cough but had never had haemoptysis. The only change in the physical signs was an extension of the pulmonary crepitations, which were now audible throughout both lungs apart from the apices. Chest expansion was $\frac{1}{2} \frac{3}{4}$ in. (1.3 to $2 \mathrm{~cm}$.). Blood 
pressure was $130 / 90 \mathrm{~mm} . \mathrm{Hg}$, and there were no signs of heart failure. A right homonomous hemianopsia was present, but there were no other abnormal neurological signs. The urine contained no abnormal constituents. The Mantoux reaction was positive in a dilution of $1: 1,000$ old tuberculin, but the sputum was persistently negative for tubercle bacilli both on direct examination and on culture. Chest $x$-ray examination showed no cardiac enlargement. Diffuse spotty opacities were distributed in the middle and lower zones of both lung fields, which appeared to spare the apices. The opacities increased towards the hila on both sides and there was thought to be some hilar gland enlargement on the right. The vital capacity $(900 \mathrm{ml}$.) and maximum ventilatory volume (29 litres per minute) were much reduced and there was considerable arterial oxygen unsaturation ( $83 \%$, falling to $72 \%$ during exercise). Serum albumin was $3.5 \mathrm{~g} . / 100 \mathrm{ml}$. and serum globulin $3.9 \mathrm{~g}$.

A probable diagnosis of pulmonary sarcoidosis was made and prednisone (50 mg. daily) was started on April 30, the dose being gradually reduced to $5 \mathrm{mg}$. daily. Considerable subjective improvement occurred but there was no convincing radiological change, only a small improvement in the pulmonary function tests, and the pulmonary crepitations persisted. Prednisone (5 mg. daily) was continued until September, when the dose was raised to $7.5 \mathrm{mg}$. daily because of increasing symptoms. Her condition remained unchanged until May, 1957, when she had a small haemoptysis. At this time the physical signs and $x$-ray appearances were unaltered. A further haemoptysis occurred in August, 1957 ; and in January, 1958, she was admitted for reassessment. At this time she was afebrile and had not lost weight. The E.S.R. was $10 \mathrm{~mm}$. Chest $x$-ray examination showed fresh infiltration at both apices in addition to that in the middle and lower zones, and an irregular cavity with surrounding collapse had appeared above and behind the first rib. The sputum contained large numbers of tubercle bacilli.

Antituberculous treatment was started and the prednisone tailed off. Recovery was slow, the sputum becoming free from tubercle bacilli in April, 1958. She was discharged home on October 10, 1958, still on antituberculous chemotherapy.

\section{Case 3}

A housewife aged 61 was first seen by Dr. R. W. Luxton in October, 1945. The history dated from her second pregnancy in 1933, following which she had a severe postpartum haemorrhage associated with a retained placenta. Subsequently she developed puerperal fever and gangrene of the left leg, necessitating amputation. After this pregnancy she never lactated, though she had breast-fed her first infant successfully. During the subsequent 15 months she had four abnormal menstrual periods followed by complete amenorrhoea. When seen in 1945 she had the classical signs and symptoms of hypopituitarism, and this diagnosis was confirmed by the investigations, which were: Hb, $64 \%$; R.B.C., 3,800,000/c.mm.; serum cholesterol, $338 \mathrm{mg} . / 100 \mathrm{ml}$.; B.M.R., $-40 \%$; urinary excretion of 17-ketosteroids in 24 hours, nil. The glucose-tolerance test gave a flat curve as follows: fasting blood sugar $66 \mathrm{mg}$./ $100 \mathrm{ml}$.; half an hour after $50 \mathrm{~g}$. of glucose by mouth $118 \mathrm{mg}$., after 1 hour $112 \mathrm{mg}$., after $1 \frac{1}{2}$ hours $102 \mathrm{mg}$., after 2 hours $79 \mathrm{mg} . / 100 \mathrm{ml}$. The insulin-sensitivity test showed hypoglycaemic unresponsiveness, and was as follows: zero blood-sugar $71 \mathrm{mg}$. $/ 100 \mathrm{ml}$., 20 minutes after 1.6 units of insulin intravenously $45 \mathrm{mg}$., after 30 minutes $37 \mathrm{mg}$., after 45 minutes $41 \mathrm{mg}$., after 1 hour $40 \mathrm{mg}$., after $1 \frac{1}{2}$ hours $45 \mathrm{mg}$., after 2 hours $41 \mathrm{mg}$. $/ 100 \mathrm{ml}$. Blood W.R. was negative and $x$-ray examination of the skull showed a normal pituitary fossa.

She responded very well to dried thyroid by mouth and returned to a fairly active life. In 1951 she stopped attending the out-patient clinic and was not seen again until May, 1958, when she was readmitted with increasing fatigue, apathy, and intolerance to cold. Clinically she appeared to be hypothyroid again, and this was confirmed by a radio-iodine uptake in the thyroid gland of $6 \%$ of the dose after two hours and of $2 \%$ after 24 hours. The serum cholesterol was high (470 mg./ $100 \mathrm{ml}$.). Radiographs showed a normal chest. Further investigations were rendered impossible by her rapid deterioration into a state of withdrawal and apathy associated with some disorientation, a refusal to take food, and incontinence. The bloodsugar at this time was $75 \mathrm{mg} . / 100 \mathrm{ml}$., the serum electrolytes were grossly disturbed (sodium $106 \mathrm{mEq} / 1$., potassium $4.3 \mathrm{mEq} / 1$., chlorides $86 \mathrm{mEq} / 1$., urea $24 \mathrm{mg}$. $/ 100 \mathrm{ml}$.). Treatment with thyroid, cortisone (100 mg. daily), and extra glucose saline drinks produced rapid improvement, and she was discharged from hospital on June 28 , feeling very well, the serum electrolytes having returned to normal. She was receiving a maintenance dose of cortisone $(25 \mathrm{mg}$. daily) and thyroid sicca 1 gr. $-65 \mathrm{mg}$.- daily.

The patient was seen regularly in the out-patient department, and on November 19 appeared quite well. Six days later, however, she became drowsy, apathetic, and incontinent following a fall at home. She was readmitted on November 27 and was found to be drowsy but easily rousable. She was slightly disorientated and very slow in answering questions. She had no cough or sputum and did not complain of headache. On examination there was slight neck-stiffness but no localizing neurological signs, the optic disks were normal, and no choroidal tubercles

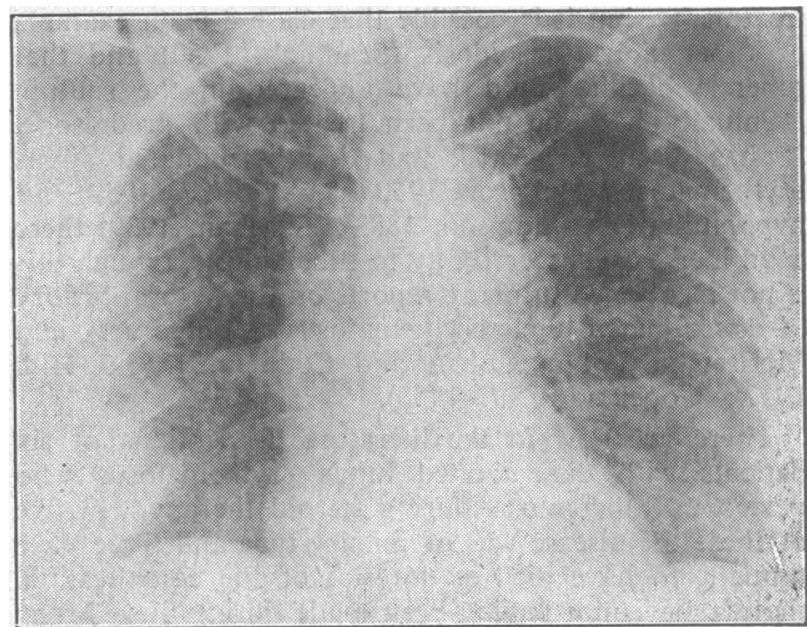

Radiograph of Case 3, showing development of bilateral apical tuberculosis with miliary spread (November, 1958) after five months' treatment with cortisone.

were visible. A few crepitations were audible at the lung bases, but there were no abnormal findings in the heart or abdomen. She remained afebrile after admission. The haemoglobin was $91 \%$, W.B.C. $9,200 / \mathrm{c} . \mathrm{mm}$. The blood sugar was $58 \mathrm{mg} . / 100 \mathrm{ml}$. Serum electrolytes and blood urea were normal. $X$-ray examination of the chest showed soft bilateral apical tuberculous opacities with miliary spread throughout both lung fields (see Fig.). These changes had appeared since the first radiograph taken in June, 1958. Lumbar puncture gave a clear fluid under pressure of $180 \mathrm{~mm}$. water and contained 16 leucocytes per c.mm. (50\% polymorphs, $50 \%$ lymphocytes), protein $135 \mathrm{mg} . /$ $100 \mathrm{ml}$., sugar $35 \mathrm{mg} . / 100 \mathrm{ml}$., chlorides $644 \mathrm{mg} . / 100 \mathrm{ml}$. No tubercle bacilli were found on direct examination.

A diagnosis of pulmonary tuberculosis with miliary spread and early tuberculous meningitis was made and appropriate treatment started. The C.S.F. has subsequently returned to normal, the radiological appearances of the lung fields are improving, and the patient is fully mobilized again and without symptoms. Treatment with cortisone, thyroid, and antituberculous chemotherapy is being continued.

\section{Discussion}

The development or dissemination of tuberculosis during steroid therapy is uncommon but nevertheless important, and has been discovered unexpectedly at 
necropsy as the cause of death on several occasions (Kleinschmidt and Johnston, 1951 ; Hill and Kirshbaum, 1956 ; Case 1). Wide dissemination of the tuberculous lesions due to haematogenous spread is a common occurrence in the recorded cases and occurred in two cases of the present report. It has been suggested (Hill and Kirshbaum, 1956) that this is due to interference by steroids with the formation of granulation or fibrous tissue and a decrease of the localizing defence reaction to tuberculosis. This opinion is supported by animal experiments (Hart and Rees, 1950 ; Spain and Molomut, 1950; Karlson and Gainer, 1951) and by post-mortem appearances in man (Davidson et al., 1953; Hill and Kirshbaum, 1956 ; Case 1), for the lesions consist largely of caseation necrosis with little or no tubercle formation. Case 1 shows the disproportion between the size of the tubercle and the amount of caseation and the absence of any attempt at repair.

None of the patients reported had a past history of tuberculosis and none had been exposed knowingly to infection. The most likely source of infection in Cases 1 and 3 is an unsuspected latent focus such as a gland, for both had normal chest $x$-ray appearances before treatment: but it is possible that Case 2 is an example of tuberculous sarcoidosis (Scadding, 1950) and that tubercle bacilli would have appeared in the sputum eventually had she not been treated with prednisone. It has been suggested that in disseminated lupus erythematosus (Harrison, 1950 ; Brit. med. J., 1959) and hypopituitarism (Simpson, 1883 ; Sheehan, 1939) there is an increased susceptibility to tuberculosis, though this is not mentioned in many reports on the natural history of disseminated lupus erythematosus (Montgomery and McCreight, 1949; Cohen and Cadman, 1953; Hill, 1957 ; Copeland et al., 1958).

There are now in the literature descriptions of six patients with disseminated lupus erythematosus who developed tuberculosis during steroid therapy. In five of these the disease was of miliary type and three were thought to have died as a result of the complication, the diagnosis not having been made during life. Many patients with disseminated lupus erythematosus require high doses of steroids to control their disease, and this may facilitate dissemination from an unsuspected focus and diminish tissue defence processes. It is possible that prophylactic antituberculous chemotherapy would prevent such an occurrence, and it is questionable whether this should be given routinely to patients with disseminated lupus erythematosus receiving steroids. I can find no report of a case of hypopituitarism developing tuberculosis during steroid treatment and, strangely, no case of Addison's disease developing disseminated tuberculosis as a result of cortisone. This may be because of the small dose usually required as replacement therapy.

The exact relationship of sarcoidosis to tuberculosis is still uncertain, though Scadding (1950) believes that a proportion of cases are tuberculous and has shown that some eventually develop a positive sputum. Steroids are, however, widely used in treatment (Whitfield, 1959 ; Shulman et al., 1952 ; Israel et al., 1954 ; Hoyle et al., 1955 ; Smellie, 1958), and of these authors only Hoyle et al. discuss the advisability of combining antituberculous therapy with steroids. Five cases of sarcoidosis developing tuberculosis during treatment with cortisone have been described previously (Small, 1951; Lovelock and Stone. 1953), and though Hoyle et al. suggest that this risk has been exaggerated a strong case for combined therapy can be made out.

The importance of making a careful search for a latent tuberculous focus, including chest radiograph, before prescribing steroids for any patient is obvious, and it may be wise to repeat the $x$-ray examination at intervals during and after treatment. Diagnosis of tuberculosis during steroid therapy may be rendered difficult by the absence of fever, the presence of a normal E.S.R. (Cases 2 and 3), and no loss of weight. Moreover, the development of tuberculosis may be difficult to differentiate from a relapse in the condition for which steroids are being given. The possibility should, however, always be considered, and particularly if respiratory symptoms, loss of weight, or fever are present.

\section{Summary}

Three cases developing tuberculosis during steroid therapy are described. In two the disease was widely disseminated.

The importance of considering this complication in any patient receiving steroids who deteriorates unexpectedly, and the difficulties of diagnosis, are stressed.

Precautions before and during treatment are suggested and the question of prophylactic antituberculous chemotherapy is discussed.

I thank Dr. R. W. Luxton and Dr. E. G. Wade for advice and for allowing me to report these cases; and Professor C. P. Campbell and Dr. S. de C. Baker for the post-mortem findings in Case 1.

\section{REFERENCES}

Brit. med. J., 1959, 1, 224.

Cohen, Sir H., and Cadman, E. F. B. (1953). Lancet, 2, 305

Copeland, G. D., von Capeller, D., and Stern, T. N. (1958). Amer. J. med. Sci., 236, 318 .

Davidson, A. G.. Fox, L., and Gold, J. J. (1953). Ann. intern. Med., 38, 852

Fred, L., Levin, M. H., Rivo, J. B., and Barrett, T. F. (1951). J. Amer. med. Ass., 147, 242.

Harris-Jones, J. N., and Pein, N. K. (1952). Lancet, 2, 115.

Harrison, T. R. (1950). Principles of Internal Medicine. Blakiston Co., New York.

Hart, P. D., and Rees, R. J. W. (1950). Lancet. 2, 391

Hill, H. M., and Kirshbaum, J. D. (1956). Ann. intern. Med., 44 781 .

Hill, L. C. (1957). Brit. med. J., 2, 655, 726

Hoyle, C., Dawson, J., and Mather, G. (1955). Lancet. 1, 638.

Israel, H. L., Sones, M., and Harrell, D. (1954). J. Amer. med. Ass., 156, 461.

Karlson, A. G., and Gainer, J. H. (1951). Dis. Chest., 20, 469.

King, E. Q., Johnson, J. B., Batten, G. S., and Henry, W. L. (1951). J. Amer. med. Ass., 147, 238.

Kleinschmidt, R. F, and Johnston, J. M. (1951). Ann. intern. Med., 35, 694.

Lovelock, F. J., and Stone, D. J. (1953). Amer. J. Med., 15, 477 Montgomery, H., and McCreight, W. G. (1949). Arch. Derm. Syph. (Chicago), 60, 356.

Popp, C. G., Ottosen, P., and Brasher, C. A. (1951). J. Amer med. Ass., 147, 241.

Scadding, J. G. (1950). Brit. med. J., 1, 745.

Sheehan, H. L. (1939). Quart. J. Med., 8, 277.

Shulman, L. E.. Schoenrich, E. H., and Harvey, A. M. (1952). Bull. Johns Hopk. Hosp., 91, 371 .

Simpson, A. R. (1883). Edinb. med. J., 28, 961.

Small, M. J. (1951). J. Amer. med. Ass., 147, 932.

Smellie, H. (1958). Brit. med. J., 2, 154.

Spain, D. M., and Molomut, N. (1950). Amer. Rev. Tuberc., 62, 337.

Whitfield, A. G. W. (1959). Brit. J. Dis. Chest., 53, 28.

Nearly 8,000 people die from accidents in the home every year. In 1957, the last year for which figures are available, there were 7,727 deaths. Of these 4,668 were due to falls, 1,263 to poisoning, 740 to burns and scalds; 696 to suffocation, and 360 to miscellaneous causes. (Royal Society for the Prevention of Accidents.) 